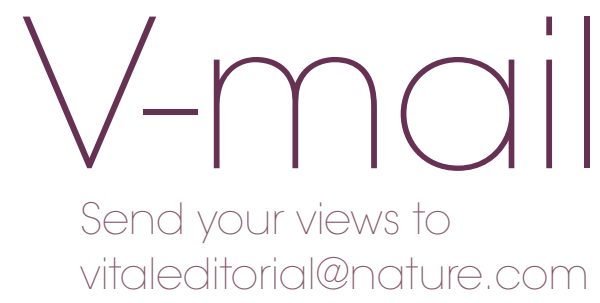

\title{
The ARF fee should be tiered
}

I have been a dental nurse for almost ten years, a job that I am passionate about. I started nursing in 2001 and took the National Examining Board Certificate for Dental Nurses in 2003. I have since gone on to take my Certificate in Radiography and also Oral Health. I have predominantly worked alongside a specialist prosthodontist, but have also nursed for a periodontist, an implantologist and other dentists. I enjoy being part of team that tries to make a difference to patients going to the dentist to have treatment. From seeing patients for their initial appointment until their final appointment, reassuring them and seeing their confidence grow, and some just having the confidence to start smiling again.

The General Dental Council opened the new register for dental care professionals in July 2006. This included dental technicians, dental hygienists/therapists and also dental nurses. By July 2008, dental nurses MUST have registered with the GDC, to allow them to continue to work. This included anyone working as a dental nurse part-time or occasionally and temporary/locum dental nurses working independently or through an agency. Dental care professionals also would need to do CPD every year and have indemnity insurance to be able to work.

The two year 'grandparenting' scheme initially cost $£ 96$, and at that time I was under the misunderstanding that the subsequent fee to register each year was still being determined but wasn't going to be as high as the initial registration fee.

When the fee was set at $£ 96.00$ for the first year to renew the registration, with the explanation that the GDC WASN'T going to increase the cost this year because of the economic climate, I was surprised to say the least.

I also subsequently learnt that dental technicians and dental hygienists/therapists pay the same amount of money to be on the register but they have the potential to earn far more than dental nurses because of their additional qualifications and training.

I am not against having to pay to be on the Register, but I do feel that the fee should be tiered according to the DCP pay scale and whether a nurse works full or part-time. I thought nurses were finally going to get the recognition they deserved, with additional responsibilities.

It is not often that something makes me feel strong enough to want to air my views but this definitely has, so much so that I started a Facebook group: 'Dental Nurses against the Annual Retention Fee. To date the group has 524 members and has had many comments, all by disillusioned dental nurses that feel like leaving the profession, because they feel like they are being penalised just for trying to do their jobs, with some retraining to do other professions. With all the extra costs from being registered, the $\mathrm{CPD}$ courses and indemnity insurance and no extra money in their wages it is hard enough for dental nurses in full-time

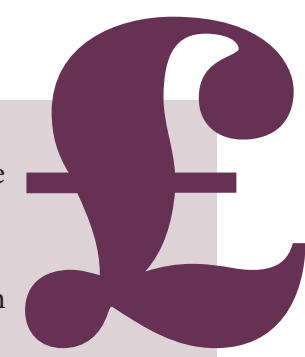
employment to pay, but for part time nurses it is even harder.

I even started a No. 10 online E-Petition which attracted almost 600 signatories before it closed this year and was submitted to the government. Their response was that it wasn't their domain and that it was up to the GDC.

This year the GDC has announced that the retention fee is set to increase to $£ 120$ from $£ 96$ next year, which is a massive 25\% increase, which when compared against the current rate of inflation of $3.1 \%$ is outrageous. Nurses already struggle to pay the existing fee, and many nurses are not even aware of this impending increase.

What exactly do nurses get for this money? After speaking to the GDC, I am told that the DCP category cannot be split down any further - why not???

As I said at the beginning, I love my job and I want to be proud to call myself a dental nurse - a registered dental nurse.

Xyanthe Lambert, Senior Dental Nurse

\section{Bevenly Hills Fonmula}

Xyanthe wins Beverly Hills Formula products worth $£ 100$.

\section{CPD in the South-West}

I always enjoy Vital and look forward to reading it. I would be grateful if you could include some of what we are doing in the South West for DCPs in the next issue.

I work for the South West Dental Postgraduate Deanery as the DCP Tutor. I work alongside two DCP advisers, Jackie Gazzard who is responsible for Dorset/Wiltshire and Sonia Jones who is responsible for Devon/
Cornwall. Between us we have been able to assist with the development of 13 local cluster CPD groups.

The groups are run by DCPs on a voluntary basis who act as a lead person(s) to organise venues, speakers etc. This allows DCPs to access core subjects and verifiable CPD local to their work/home at a low cost.

Each group is part supported financially by the South West Dental Postgraduate Deanery and also by the DCP tutor/adviser in the area.

We also provide a day each year for the group leads to meet, discuss and network.

Details of all the groups can be found on our website www.bristol.ac.uk/dentalpg/. You can also email me if you require any further information, on omxdb@bristol.ac.uk.

Diane Bell, Dental Care Professional Tutor South West Dental Postgraduate Deanery 